\title{
Shifting paradigms of nontuberculous mycobacteria in cystic fibrosis
}

\author{
Tavs Qvist ${ }^{*}$, Tania Pressler ${ }^{1}$, Niels Høiby ${ }^{2}$ and Terese L Katzenstein ${ }^{1}$
}

\begin{abstract}
Important paradigms of pulmonary disease with nontuberculous mycobacteria (NTM) are currently shifting based on an increasing attention within the field of cystic fibrosis (CF). These shifts are likely to benefit the management of all patients with pulmonary NTM, regardless of underlying pathology. Currently several key areas are being revised: The first outbreak of human NTM transmission has been proven and new evidence of biofilm growth in vivo has been demonstrated. A better understanding of the clinical impact of NTM infection has led to increased diagnostic vigilance and new recommendations for lung transplantation are under way. While recent changes have reinvigorated the interest in NTM disease, the challenge remains, whether such advances can be successfully translated into improved management and care.
\end{abstract}

Keywords: NTM, Nontuberculous mycobacteria, Cystic fibrosis, MABSC, MAC, Mycobacterium, Abcessus, Avium, Massiliense, Environmental mycobacteria, MOT, Biofilm, Transmission, Lung transplantation

\section{Background}

Announced as the most important emerging threat to cystic fibrosis (CF) patients at the 2013 European Cystic Fibrosis Conference, the perception of nontuberculous mycobacteria (NTM) disease has once again undergone a notable shift. Previously thought of as a group of rather benign environmental bacteria associated with random colonization and only rarely with genuine infection of the airway [1], perceptions have now changed. Mycobacterium abscessus Complex (MABSC) and Mycobacterium avium Complex (MAC) are now recognized as insidious opportunists that can seriously affect morbidity and mortality in CF. Fundamental paradigms of NTM pulmonary disease concerning clinical impact, patient susceptibility, transmission, bacterial modes of growth and implications for lung transplantation are currently being revised. Such issues are not unique to $\mathrm{CF}$ and can be expected to affect NTM management in patients with other underlying pulmonary diseases. While great leaps have been made in understanding the scope and impact of NTM infections, advances in diagnostics and antibiotic management have been less impressive and still

\footnotetext{
*Correspondence: tavs.qvist@gmail.com

'Department of Infectious Diseases, Cystic Fibrosis Center Copenhagen, Copenhagen University Hospital Rigshospitalet, Copenhagen, Denmark Full list of author information is available at the end of the article
}

await the benefits of the heightened attention NTM disease is now receiving. Since 2007, the American Thoracic Society (ATS)'s and the Infectious Disease Society of America (IDSA)'s comprehensive statement on NTM disease has been the principle guide of management [2]. 2014 appears to be the year where the eagerly expected CF specific NTM guidelines will be published, hopefully building further consensus in a field void of solid empirical evidence and highlighting areas in urgent need of attention.

\section{Biofilm growth}

New evidence that rapidly growing NTM can grow in vivo as biofilms on intravascular catheters [3] could be an indication that biofilm growth in pulmonary NTM disease might also be a concern. Emerging evidence that pulmonary Mycobacterium tuberculosis (TB) is a biofilm infection [4] and our group's recent examination of explanted CF lungs from patients with MABSC [5], suggests that this might indeed be the case. MABSC has been shown to be capable of structured cord formation, a biofilm mode of growth, associated with the morphologically distinct rough growth pattern [6,7]. This pattern is assumed to be similar to that proven for TB [8], suggesting that biofilm formation, is an inherent part of NTM pathogenesis in pulmonary disease. While phenotype 
switching of MABSC from smooth to rough has been linked to increased virulence [9], data on the genetic determinants of cord formation remain sparse. Future strategies might include using transposons for insertional mutagenesis [10], experimental lung models and sequential sequencing [11]. Addressing whether in vivo biofilm growth takes place in the CF lung could prove pivotal in explaining the notorious unreliability of in vitro susceptibility testing. The discrepancy between in vitro antibiotic resistance and the clinical benefit of treatment suggests that more than just antibiotic resistance is involved and that antibiotic tolerance, inferred by a protective biofilm coat could be present, in parallel with what is observed in other chronic infections [12,13]. Demonstrating NTM biofilm growth in the human lung could also open up new treatment opportunities as biofilm disrupting targets could be systematically examined, something that has not previously been attempted for NTM.

\section{Diagnostic challenges and opportunities}

Identifying patients with NTM and clinical deterioration is difficult, but important, as these are the once most likely to benefit from antimycobacterial treatment. While conventional culture and acid-fast microscopy remain the backbone of mycobacterial diagnostics, some changes are under way, which could affect both the sensitivity and specificity of NTM diagnostics. New recommendations on NTM diagnostics are likely to include shorter time from sampling to culture, increased focus on routine screening, centralization of testing to larger mycobacteriological reference laboratories and validated pretreatment of samples to avoid Gram negative bacterial or fungal overgrowth. Several of these principles are already recommended, but not universally implemented [2]. MABSC, also called Mycobacterium abscessus sensu lato comprises the closely related species Mycobacterium asbcessus sensu stricto, Mycobacterium massiliense and Mycobacterium bolletii. Differentiation of the MABSC subspecies is difficult [14], and most clinical laboratories report infection with any of the three merely as $M$. abscessus. Historical variability in NTM taxonomy has only added to the confusion of how to correctly classify members of MABSC and MAC. Advances in molecular diagnostics and whole genome sequencing in particular, promise a brighter future for speciation, which is important in light of new insights into differences in virulence between subspecies. Importantly the subspecies $M$. massiliense remains susceptible to macrolides even after prolonged exposure, resulting from an inactivating erm (41) deletion [15]. Finally, immunological assays could prove useful as a means of monitoring NTM disease progression in a fashion similar to assays used in Pseudomonas aeruginosa infections in CF [16,17]. Thus, assays utilizing MABSC antigens-to-patient serum IgG have been shown to correlate with clinical disease
$[18,19]$ and are currently being explored further for clinical use [20].

\section{Prevalence and clinical impact}

Reported prevalence rates have varied over time and geographically and are summarized in Table 1.

Generally there has been a tendency towards higher prevalence rates being reported over time with a median prevalence rate of 9\% (IQR: 3 - 11\%) in the 9 studies initiated before 2000 and 13\% (IQR: $7-17 \%$ ) for the 10 post millennium prevalence studies. The reasons for this possible rise in NTM prevalence remain unknown, but could include changes in surveillance strategies although many centers are adamant that is not the case. Other reasons could include greater exposure [38], changes in the lung flora due to inhaled antibiotics [39], and reduced host immunity through autophagy inhibition during azithromycin treatment [40] or patient-to-patient transmission [15].

North American studies have consistently reported a higher proportion of MAC compared to MABSC [41], whereas the opposite is true for Western European studies [42], but the reasons for these geographical differences remain elusive. Another trend with some consistency, is that MABSC species, while isolated at all ages, seem to peak in prevalence in children, while MAC reaches the highest prevalence among adults [30,43,44], although this paradigm has been challenged [41]. Catherinot et al. have proposed that patient susceptibility might play a bigger role than previously thought, specifically pointing to an association between MABSC and more severe forms of CF [43]. Improved epidemiological surveillance such as the recent inclusion of NTM microbiology in the European CF registry will certainly be helpful in designing studies with the size required to address these questions.

While chronic MAC is not considered a critical threat to patient health, isolation of MABSC is often a real cause for concern. Some patients are diagnosed early on a routine mycobacterial culture, suggesting an initial phase of low to no clinical impact, which predates later loss of lung function [45]. Others develop chronic MABSC infection which can cause severe, sometimes fatal lung disease, even after an indolent period of several years [46]. A 2010 study from the US found that those infected with MABSC had a more rapid decline in lung function than their uninfected counterparts (3\% per year vs. $2 \%$ per year) [29]. While the association with poor lung function is well established, the question of whether infection is mostly a consequence of, or a predisposing factor for poor lung function, remains unanswered. A 2014 study suggests that the rate of decline in FEV1 in the year leading up to the first positive culture may help distinguish patients who progress to active NTM disease and require treatment [41]. This study also 
Table 1 Studies reporting the prevalence of nontuberculous mycobacteria in cystic fibrosis populations

\begin{tabular}{|c|c|c|c|c|c|c|c|c|}
\hline Study & Study year & Location & Design & Included CF patients & NTM cases & NTM revalence & $\%$ MABSC & $\%$ MAC \\
\hline Boxerbaum B. & 1980 & $\mathrm{OH}$, USA & Prospective & 430 & 8 & 1.8 & $75^{*}$ & 0 \\
\hline Smith MJ et al. [21] & 1984 & UK & Prospective & 223 & 4 & 1.8 & $25^{*}$ & 0 \\
\hline Hjelte L et al. [22] & 1990 & Sweden & Prospective & 54 & 5 & 9.2 & 0 & 60 \\
\hline Kilby JM et al. [23] & 1992 & NC, USA & Prospective & 87 & 17 & 19.5 & $29^{*}$ & 76 \\
\hline Aitken ML et al. [24] & 1993 & WA, USA & Prospective & 64 & 8 & 12.5 & 0 & 88 \\
\hline Hjelt K et al. [25] & 1994 & Denmark & Prospective & 185 & 7 & 3.8 & $71^{*}$ & 29 \\
\hline Sermet-Gaudelus I et al. [26] & 1996-99 & France & Prospective & 296 & 29 & 9.8 & 52 & 21 \\
\hline Fauroux B et al. [27] & 1997 & France & Prospective & 106 & 7 & 6.6 & $43^{*}$ & 0 \\
\hline Mussaffi H et al. [28] & 1997-02 & Israel & Retrospective & 139 & 12 & 8.6 & $67 \S$ & $25 \S$ \\
\hline Esther CR Jr et al. [29] & $2000-07$ & NC, USA & Registry & 1,216 & 166 & 13.7 & 41 & 59 \\
\hline Pierre-Audigier C et al. [30] & 2000 & France & Prospective & 385 & 31 & 8.1 & 42 & 23 \\
\hline Oliver A et al. [19] & 2000 & Spain & Prospective & 37 & 6 & 16.2 & $50^{*}$ & 33 \\
\hline Radhakrishnan et al. [31] & 2004 & Canada & Prospective & 98 & 6 & 6.1 & 33 & 67 \\
\hline Levy I et al. [32] & 2001-03 & Israel & Cross-sectional & 186 & 42 & 22.6 & 31 & 14 \\
\hline Olivier KN et al. [33] & 2002 & USA & Prospective & 986 & 128 & 13.0 & 20 & 72 \\
\hline Roux AL et al. [34] & 2004 & France & Prospective & 1,582 & 104 & 6.6 & 48 & 22 \\
\hline Valenza et al. [35] & 2006 & Germany & Prospective & 60 & 8 & 13.3 & 50 & 50 \\
\hline Chalermskulrat W et al. [36] & 2006 & $\mathrm{OH}$, USA & Retrospective & 132 & 26 & 19.7 & 46 & 50 \\
\hline Binder AM et al. [37] & 2011 & USA & Registry & 5,403 & 191 & 3.5 & 36 & 64 \\
\hline
\end{tabular}

${ }^{*}=$ M. chelonae reported, but is here included as MABSC due to historical changes in taxonomy. $\S=$ percentage based on 6 chronic NTM cases.

reported that a quarter of patients cleared their NTM spontaneously [41] suggesting three phases of infection: Transient, persistent and active. Why some patients clear NTM suddenly without treatment, while others deteriorate rapidly warrants further investigation, as identifying who and when to treat remains the clinician's central challenge in NTM management.

\section{Transmission}

The first solid evidence of patient-to-patient transmission of NTM in a UK CF center was published in 2013 [15]. The authors used whole-genome sequencing and showed, with a reasonable degree of certainty that the MABSC subsp. massiliense had spread within their center. Out of 31 patients nine shared one genetically nearidentical strain and two patients shared another strain. A convincing case for in- and out-patient overlap as well as careful elimination of potential sources of contamination (such as the water supply and bronchoscopy equipment) was performed. The study thus confirms suspicions raised in a report from Seattle, USA, that indicated possible transmission of a single strain of $M$. massiliense, identified through the use of pulse-field gel electrophoresis and PCR [47] and a similar, but less cited report from Sweden [48]. Mapping the genetic population structure of MABSC is an urgent issue currently being examined by Floto et al. in a multicenter study. This is expected to have significant impact on how infection control is managed in the in- and out-patient clinic.

\section{Lung transplantation}

The view that NTM constitute an absolute contraindication for lung transplantation is being modified $[49,50]$. Reports on outcome following lung transplantation in CF patients with NTM infection are few and the impact on mortality remains unknown, although increased morbidity is consistently reported $[49,51]$. While aggressive treatment is recommended [2], eradication prior to transplantation is often unrealistic. Despite this, NTM disease does not preclude successful recovery after transplantation and new recommendations are expected to reflect this, bringing hope to a small, but growing number of patients, in desperate need of lung transplantation.

\section{Antibiotic treatment}

Since the important shift in the 1990s away from antituberculous regimes towards macrolide based multidrug therapy [52], not much new has been accomplished in the field of antibiotic treatment of NTM. A part from a current phase 2 trial of inhaled amikacin in the US, a recent Cochrane Review concluded, that not a single randomized trial comparing antibiotic treatment of NTM lung infection in CF has been completed [53]. NTM are notoriously difficult to treat and require multidrug 
treatment for 12 months or more. At present, ATS guidelines are widely accepted as the standard of care [2], but there are several ongoing controversies about MAC and MABSC disease that could benefit from an updated consensus. The superiority of one macrolide over another has not been demonstrated for MAC lung disease, nor has the benefit of routinely including an IV drug (amikacin) early on been demonstrated [2] and both issues remain undecided for newly diagnosed MAC. A preliminary trial from a non-CF setting suggests that a two-drug regimen of clarithromycin and ethambutol may be non-inferior to the recommended threedrug regimen, which today includes rifampicin [54].

The duration and intensity of antibiotic treatment for MABSC, especially in patients that do not clear the bacteria, remains a headache for most clinicians. Inhaled therapy is increasingly used in MABSC regimens and a recent retrospective study of inhaled amikacin found that while reductions in smear positivity and some symptomatic improvement were observed, toxicity was not uncommon [55]. Hopefully, preliminary results from the ongoing phase 2 trial of inhaled liposomal amikacin will be released in 2014. New CF specific treatment guidelines under way are not expected to change the fundamental structure of past MABSC recommendations, which consist of an initial induction phase followed by long maintenance therapy, but new regimens will likely include longer induction phases and generally more antibiotics, with azithromycin as the macrolide of choice. NTM specific drug-drug interactions, medication side-effects and nonadherence are also areas receiving fresh attention.

\section{Conclusions}

NTM seem to have found a successful niche in the structurally complex and often antibiotic rich environment of the CF lung. The central paradigms of how pulmonary NTM infection is initiated and how the disease progresses and interacts with the host have all shifted within the last years and upcoming consensus documents are eagerly awaited. While recent changes in the understanding of NTM disease have reinvigorated the field, the challenge remains, if such advances can be successfully translated into improved management and care.

\section{Abbreviations \\ CF: Cystic fibrosis; NTM: Nontuberculous mycobacteria; MABSC: Mycobacterium abscessus complex; MAC: Mycobacterium avium complex; ATS: American Thoracic Society; IDSA: Infectious Disease Society of America; TB: Tuberculosis; IV: Intravenous.}

\section{Competing interests}

The authors declare that they have no competing interests.

\section{Authors' contributions}

Manuscript was drafted by TQ and TLK. Concept was developed in

collaboration with TP and $\mathrm{NH}$ who assisted in revision of the manuscript. All authors have seen and approved the finished manuscript. The manuscript has not previously been published nor is it being considered for publication elsewhere.

\section{Author details}

${ }^{1}$ Department of Infectious Diseases, Cystic Fibrosis Center Copenhagen, Copenhagen University Hospital Rigshospitalet, Copenhagen, Denmark. ²Department of Clinical Microbiology, University Hospital Rigshospitalet, Copenhagen, Denmark.

Received: 1 November 2013 Accepted: 4 April 2014

Published: 11 April 2014

\section{References}

1. Torrens JK, Dawkins P, Conway SP, Moya E: Non-tuberculous mycobacteria in cystic fibrosis. Thorax 1998, 53(0040-6376 (Print)):182-185.

2. Griffith DE, Aksamit T, Brown-Elliott B a, Catanzaro A, Daley C, Gordin F, Holland SM, Horsburgh R, Huitt G, lademarco MF, Iseman M, Olivier K, Ruoss S, von Reyn CF, Wallace RJ, Winthrop K, Wallace RJ Jr: An official ATS/IDSA statement: diagnosis, treatment, and prevention of nontuberculous mycobacterial diseases. Am J Respir Crit Care Med 2007, 175:367-416.

3. El HG, Viola GM, Hachem R, Han XY, Raad II: Rapidly growing mycobacterial bloodstream infections. Lancet Infect Dis 2013, 13(1474-4457 (Electronic)):166-174.

4. Kulka K, Hatfull G, Ojha AK: Growth of Mycobacterium tuberculosis Biofilms. J Vis Exp 2012, 60(60):e3820. doi:10.3791/3820.

5. Qvist T, Eickhardt-Sørensen S, Pressler T, Katzenstein TL, Andersen CB, Iversen M, Bjarnsholt T, Hoiby N: First evidence of Mycobacterium abscessus biofilm in the lungs of chronically infected CF patients. J Cyst Fibros 2013, 12(Suppl. 1):S2-S2.

6. Jönsson BE, Bylund J, Johansson BR, Telemo E, Wold AE: Cord-forming mycobacteria induce DNA meshwork formation by human peripheral blood mononuclear cells. Pathog Dis 2013, 67:54-66.

7. Howard ST, Rhoades E, Recht J, Pang X, Alsup A, Kolter R, Lyons CR, Byrd TF: Spontaneous reversion of Mycobacterium abscessus from a smooth to a rough morphotype is associated with reduced expression of glycopeptidolipid and reacquisition of an invasive phenotype. Microbiology 2006, 152(Pt 6):1581-1590.

8. Giovannini D, Cappelli G, Jiang L, Castilletti C, Colone A, Serafino A, Wannenes F, Giaco L, Quintiliani G, Fraziano M, Nepravishta R, Colizzi V, Mariani F: A new Mycobacterium tuberculosis smooth colony reduces growth inside human macrophages and represses PDIM Operon gene expression. Does an heterogeneous population exist in intracellular mycobacteria? Microb Pathog 2012, 53(1096-1208 (Electronic)):135-146.

9. Catherinot E, Clarissou J, Etienne G, Ripoll F, Emile J-FF, Daffé M, Perronne C, Soudais C, Gaillard J-LL, Rottman M, Daffe M: Hypervirulence of a rough variant of the Mycobacterium abscessus type strain. Infect Immun 2007, 75:1055-1058.

10. Pang JM, Layre E, Sweet L, Sherrid A, Moody DB, Ojha A, Sherman DR: The polyketide Pks1 contributes to biofilm formation in Mycobacterium tuberculosis. J Bacteriol 2012, 194:715-721.

11. Kreutzfeldt KM, McAdam PR, Claxton P, Holmes A, Seagar AL, Laurenson IF, Fitzgerald JR: Molecular longitudinal tracking of Mycobacterium abscessus spp. during chronic infection of the human lung. PLoS One 2013, 8:e63237.

12. Bjarnsholt T, Jensen PO, Fiandaca MJ, Pedersen J, Hansen CR, Andersen CB, Pressler T, Givskov M, Hoiby N: Pseudomonas aeruginosa biofilms in the respiratory tract of cystic fibrosis patients. Pediatr Pulmonol 2009, 44(1099-0496 (Electronic)):547-558.

13. Hoiby N, Ciofu O, Johansen HK, Song ZJ, Moser C, Jensen PO, Molin S, Givskov M, Tolker-Nielsen T, Bjarnsholt T: The clinical impact of bacterial biofilms. Int J Oral Sci 2011, 3(1674-2818 (Print)):55-65.

14. Zelazny AM, Root JM, Shea YR, Colombo RE, Shamputa IC, Stock F, Conlan S, McNulty S, Brown-Elliott BA, Wallace RJ Jr, Olivier KN, Holland SM, Sampaio EP: Cohort study of molecular identification and typing of Mycobacterium abscessus, Mycobacterium massiliense, and Mycobacterium bolletii. J Clin Microbiol 2009, 47(1098-660X (Electronic)):1985-1995.

15. Bryant JM, Grogono DM, Greaves D, Foweraker J, Roddick I, Inns T, Reacher M, Haworth CS, Curran MD, Harris SR, Peacock SJ, Parkhill J, Floto RA: Whole-genome sequencing to identify transmission of Mycobacterium 
abscessus between patients with cystic fibrosis: a retrospective cohort study. Lancet 2013, 381(1474-547X (Electronic)):1551-1560.

16. Pressler T, Karpati F, Granström M, Knudsen PK, Lindblad A, Hjelte L, Olesen HV, Meyer P, Høiby N, Granstrom M, Hoiby N: Diagnostic significance of measurements of specific $\lg G$ antibodies to Pseudomonas aeruginosa by three different serological methods. J Cyst Fibros 2009, 8(1569-1993 (Print)):37-42.

17. Pressler T, Bohmova C, Conway S, Dumcius S, Hjelte L, Hoiby N, Kollberg H, Tummler B, Vavrova V: Chronic Pseudomonas aeruginosa infection definition: EuroCareCF Working Group report. J Cyst Fibros 2011, 10 Suppl(10 Suppl):S75-S78. 1873-5010 (Electronic).

18. Ferroni A, Sermet-Gaudelus I, Le Bourgeois M, Pierre-Audigier C, Offredo C, Rottman M, Guillemot D, Bernède C, Vincent V, Berche P, Gaillard J-LL, Le $B M$, Bernede C: Measurement of immunoglobulin $G$ against Mycobacterial antigen $\mathrm{A} 60$ in patients with cystic fibrosis and lung infection due to Mycobacterium abscessus. Clin Infect Dis 2005, 40(1537-6591 (Electronic)): 58-66. 1537-6591 (Electronic).

19. Oliver A, Maiz L, Canton R, Escobar H, Baquero F, Gomez-Mampaso E: Nontuberculous mycobacteria in patients with cystic fibrosis. Clin Infect Dis 2001, 32(1058-4838 (Print)):1298-1303.

20. Qvist T, Pressler T, Katzenstein TL, Hoiby N: Elevated levels of antibodies against Mycobacterium abscessus in cystic fibrosis patients is associated with active lung disease. Pediatr Pulmonol 2012, 3(47 Suppl):335. 1099-0496 (Electronic).

21. Smith MJ, Efthimiou J, Hodson ME, Batten JC: Mycobacterial isolations in young adults with cystic fibrosis. Thorax 1984, 39:369-375.

22. Hjelte L, Petrini B, Källenius G, Strandvik B, Kallenius G: Prospective study of mycobacterial infections in patients with cystic fibrosis. Thorax 1990 45(0040-6376 (Print)):397-400.

23. Kilby JM, Gilligan PH, Yankaskas JR, Highsmith WE Jr, Edwards LJ, Knowles MR: Nontuberculous mycobacteria in adult patients with cystic fibrosis. Chest 1992, 102(0012-3692 (Print)):70-75.

24. Aitken ML: Nontuberculous mycobacterial disease in adult cystic fibrosis patients. CHEST J 1993, 103:1096.

25. Hjelt K, Hojlyng N, Howitz P, Illum N, Munk E, Valerius NH, Fursted K, Hansen KN, Heltberg I, Koch C: The role of Mycobacteria Other Than Tuberculosis (MOTT) in patients with cystic fibrosis. Scand J Infect Dis 1994, 26(0036-5548 (Print)):569-576.

26. Sermet-Gaudelus I, Le Bourgeois M, Pierre-Audigier C, Offredo C, Guillemot D, Halley S, Akoua-Koffi C, Vincent V, Sivadon-Tardy V, Ferroni A, Berche P, Scheinmann P, Lenoir G, Gaillard J-LL, Le BM: Mycobacterium abscessus and children with cystic fibrosis. Emerg Infect Dis 2003, 9:1587-1591.

27. Fauroux B, Delaisi B, Clément A, Saizou C, Moissenet D, Truffot-Pernot C, Tournier G, Vu Thien H: Mycobacterial lung disease in cystic fibrosis: a prospective study. Pediatr Infect Dis J 1997, 16:354-358.

28. Mussaffi H, Rivlin J, Shalit I, Ephros M, Blau H: Nontuberculous mycobacteria in cystic fibrosis associated with allergic bronchopulmonary aspergillosis and steroid therapy. Eur Respir J 2005 25(0903-1936 (Print)):324-328.

29. Esther CR Jr, Esserman DA, Gilligan P, Kerr A, Noone PG, Esther CR: Chronic Mycobacterium abscessus infection and lung function decline in cystic fibrosis. J Cyst Fibros 2010, 9:117-123.

30. Pierre-Audigier C, Ferroni A, Sermet-Gaudelus I, Le BM, Offredo C, Vu-Thien H, Fauroux B, Mariani P, Munck A, Bingen E, Guillemot D, Quesne G, Vincent $\checkmark$, Berche P, Gaillard JL: Age-related prevalence and distribution of nontuberculous mycobacterial species among patients with cystic fibrosis. J Clin Microbiol 2005, 43(0095-1137 (Print)):3467-3470.

31. Radhakrishnan DK, Yau Y, Corey M, Richardson S, Chedore P, Jamieson F, Dell SD: Non-tuberculous mycobacteria in children with cystic fibrosis: isolation, prevalence, and predictors. Pediatr Pulmonol 2009, 44:1100-1106.

32. Levy I, Grisaru-Soen G, Lerner-Geva L, Kerem E, Blau H, Bentur L, Aviram M, Rivlin J, Picard E, Lavy A, Yahav Y, Rahav G: Multicenter cross-sectional study of nontuberculous mycobacterial infections among cystic fibrosis patients, Israel. Emerg Infect Dis 2008, 14:378-384.

33. Olivier KN, Weber DJ, Wallace RJ Jr, Faiz AR, Lee JH, Zhang Y, Brown-Elliot BA, Handler A, Wilson RW, Schechter MS, Edwards LJ, Chakraborti S, Knowles MR: Nontuberculous mycobacteria. I: multicenter prevalence study in cystic fibrosis. Am J Respir Crit Care Med 2003, 167(1073-449X (Print)):828-834.

34. Roux AL, Catherinot E, Ripoll F, Soismier N, Macheras E, Ravilly S, Bellis G, Vibet MA, Le RE, Lemonnier L, Gutierrez C, Vincent V, Fauroux B, Rottman M,
Guillemot D, Gaillard JL: Multicenter study of prevalence of nontuberculous mycobacteria in patients with cystic fibrosis in france. J Clin Microbiol 2009, 47(1098-660X (Electronic)):4124-4128.

35. Valenza G, Tappe D, Turnwald D, Frosch M, König C, Hebestreit H, Abele-Horn M: Prevalence and antimicrobial susceptibility of microorganisms isolated from sputa of patients with cystic fibrosis. J Cyst Fibros 2008, 7:123-127.

36. Chalermskulrat W, Sood N, Neuringer IP, Hecker TM, Chang L, Rivera MP, Paradowski $\sqcup$, Aris RM: Non-tuberculous mycobacteria in end stage cystic fibrosis: implications for lung transplantation. Thorax 2006, 61(0040-6376 (Print)):507-513.

37. Binder AM, Adjemian J, Olivier KN, Prevots DR: Epidemiology of nontuberculous mycobacterial infections and associated chronic macrolide use among persons with cystic fibrosis. Am J Respir Crit Care Med 2013, 188:807-812.

38. Feazel LM, Baumgartner LK, Peterson KL, Frank DN, Harris JK, Pace NR: Opportunistic pathogens enriched in showerhead biofilms. Proc Natl Acad Sci USA 2009, 106(1091-6490 (Electronic)):16393-16399.

39. Saiman L, Siegel J: Infection control in cystic fibrosis. Clin Microbiol Rev 2004, 17(0893-8512 (Print)):57-71.

40. Renna M, Schaffner C, Brown K, Shang S, Tamayo MH, Hegyi K, Grimsey NJ, Cusens D, Coulter S, Cooper J, Bowden AR, Newton SM, Kampmann B, Helm J, Jones A, Haworth CS, Basaraba RJ, Degroote MA, Ordway DJ, Rubinsztein DC, Floto RA: Azithromycin blocks autophagy and may predispose cystic fibrosis patients to mycobacterial infection. I Clin Invest 2011, 121(1558-8238 (Electronic)):3554-3563.

41. Martiniano SL, Sontag MK, Daley CL, Nick JA, Sagel SD: Clinical significance of a first positive nontuberculous mycobacteria culture in cystic fibrosis. Ann Am Thorac Soc 2014, 11:36-44.

42. Russell CD, Claxton P, Doig C, Seagar A-L, Rayner A, Laurenson IF: Non-tuberculous mycobacteria: a retrospective review of Scottish isolates from 2000 to 2010. Thorax 2013, Epub ahead of print.

43. Catherinot E, Roux AL, Vibet MA, Bellis G, Ravilly S, Lemonnier L, Le RE, Bernede-Bauduin C, Le BM, Herrmann JL, Guillemot D, Gaillard JL: Mycobacterium avium and Mycobacterium abscessus complex target distinct cystic fibrosis patient subpopulations. J Cyst Fibros 2013, 12(1873-5010 (Electronic)):74-80.

44. Esther CR Jr, Henry MM, Molina PL, Leigh MW: Nontuberculous mycobacterial infection in young children with cystic fibrosis. Pediatr Pulmonol 2005, 40(8755-6863 (Print)):39-44.

45. Olivier KN, Weber DJ, Lee J-HH, Handler A, Tudor G, Molina PL, Tomashefsk J, Knowles MR: Nontuberculous mycobacteria. II: nested-cohort study of impact on cystic fibrosis lung disease. Am J RespirCrit Care Med 2003, 167(1073-449X (Print)):835-840.

46. Cullen AR, Cannon CL, Mark EJ, Colin AA: Mycobacterium abscessus infection in cystic fibrosis. Colonization or infection? Am J RespirCrit Care Med 2000, 161(1073-449X (Print)):641-645.

47. Aitken ML, Limaye A, Pottinger P, Whimbey E, Goss CH, Tonelli MR, Cangelosi GA, Dirac MA, Olivier KN, Brown-Elliott BA, McNulty S, Wallace RJ $J$ r: Respiratory outbreak of Mycobacterium abscessus subspecies massiliense in a lung transplant and cystic fibrosis center. Am J RespirCrit Care Med 2012, 185(1535-4970 (Electronic)):231-232.

48. Jonsson BE, Gilljam M, Lindblad A, Ridell M, Wold AE, Welinder-Olsson C: Molecular epidemiology of Mycobacterium abscessus, with focus on cystic fibrosis. J Clin Microbiol 2007, 45(0095-1137 (Print)):1497-1504.

49. Qvist T, Pressler T, Thomsen VO, Skov M, Iversen M, Katzenstein TL: Nontuberculous Mycobacterial Disease Is Not a Contraindication to Lung Transplantation in Patients with Cystic Fibrosis: A Retrospective Analysis in a Danish Patient Population. Transplant Proc 2012, 45(1873-2623 (Electronic)):342-345.

50. Gilljam M, Schersten $H$, Silverborn M, Jonsson B, Ericsson HA: Lung transplantation in patients with cystic fibrosis and Mycobacterium abscessus infection. J Cyst Fibros 2010, 9(1873-5010 (Electronic)):272-276.

51. Chernenko SM, Humar A, Hutcheon M, Chow CW, Chaparro C, Keshavjee S, Singer LG: Mycobacterium abscessus infections in lung transplant recipients: the international experience. J Heart Lung Transplant 2006, 25(1557-3117 (Electronic)):1447-1455.

52. Griffith DE: Therapy of nontuberculous mycobacterial disease. Curr Opin Infect Dis 2007, 20(0951-7375 (Print)):198-203.

53. Waters V, Ratjen F: Antibiotic treatment for nontuberculous mycobacteria lung infection in people with cystic fibrosis. Cochrane Database Syst Rev 2012, 12(1469-493X (Electronic)):CD010004. 
54. Miwa S, Shirai M, Toyoshima M, Shirai T, Yasuda K, Yokomura K, Yamada T, Masuda M, Inui N, Chida K, Suda T, Hayakawa H: Efficacy of clarithromycin and ethambutol for Mycobacterium avium complex pulmonary disease. A preliminary study. Ann Am Thorac Soc 2014, 11:23-9.

55. Olivier KN, Shaw PA, Glaser TS, Bhattacharyya D, Fleshner M, Brewer CC, Zalewski CK, Folio LR, Siegelman JR, Shallom S, Park IK, Sampaio EP, Zelazny AM, Holland SM, Prevots DR: Inhaled amikacin for treatment of refractory pulmonary nontuberculous mycobacterial disease. Ann Am Thorac Soc 2014, 11:30-5.

doi:10.1186/1465-9921-15-41

Cite this article as: Qvist et al: Shifting paradigms of nontuberculous

mycobacteria in cystic fibrosis. Respiratory Research 2014 15:41.

\section{Submit your next manuscript to BioMed Central and take full advantage of:}

- Convenient online submission

- Thorough peer review

- No space constraints or color figure charges

- Immediate publication on acceptance

- Inclusion in PubMed, CAS, Scopus and Google Scholar

- Research which is freely available for redistribution 